\section{Challenges to the Future}

\section{Conservation of the Antarctic}

\author{
S. L. Chown, ${ }^{1,2 *} \dagger$ J. E. Lee, ${ }^{1}$ K. A. Hughes, ${ }^{3}$ J. Barnes, ${ }^{4}$ P. J. Barrett, ${ }^{5}$ D. M. Bergstrom, ${ }^{6}$ \\ P. Convey ${ }^{3}$ D. A. Cowan, ${ }^{7}$ K. Crosbie,${ }^{8}$ G. Dyer ${ }^{9}$ Y. Frenot, ${ }^{10,11}$ S. M. Grant ${ }^{3}$ D. Herr, ${ }^{12}$ \\ M. C. Kennicutt II, ${ }^{13}$ M. Lamers, ${ }^{14}$ A. Murray ${ }^{15}$ H. P. Possingham ${ }^{16}$ K. Reid, ${ }^{17}$ M. J. Riddle, ${ }^{6}$ \\ P. G. Ryan, ${ }^{18}$ L. Sanson, ${ }^{19}$ J. D. Shaw, ${ }^{6,16}$ M. D. Sparrow, ${ }^{20}$ C. Summerhayes, ${ }^{21}$ A. Terauds, ${ }^{6}$ \\ D. H. Wal|22
}

$\mathrm{T}$ he Antarctic Treaty System, acknowledged as a successful model of cooperative regulation of one of the globe's largest commons (1), is under substantial pressure. Concerns have been raised about increased stress on Antarctic systems from global environmental change and growing interest in the region's resources $(2,3)$. Although policy-makers may recognize these challenges, failure to respond in a timely way can have substantial negative consequences. We provide a horizon scan, a systematic means for identifying emerging trends and assisting decision-makers in identifying policies that address future challenges $(2,3)$. Previous analyses of conservation threats in the Antarctic have been restricted to matters for which available evidence is compelling (4). We reconsider these concerns because they might escalate quickly, judging from recent rapid environmental change in parts of Antarctica and increasing human interest in the region (see the map). We then focus on a more distant time horizon.

The most immediate conservation threats to species, ecosystems, and resources around the Antarctic margin are consequences of regional warming, ocean acidification, and changes in sea-ice distribution. Marine resource extraction may exacerbate these threats. Current information suggests that toothfish and krill are particularly at risk into the future, but the full extent thereof is unclear due to the lack of comprehensive understanding of their life histories and spatial dynamics and difficulties in obtaining such information (5). Advancing marine ecosystem protection, which may help ensure that resource extraction is conducted in a more sustainable fashion, is a major governance challenge.

Climate change is elevating risks of introduction of nonindigenous species that might become invasive (6). These risks will be exacerbated should tourist and research activity in the region continue to increase. The nonindigenous species threat is better recognized than any other in the region and has been addressed most comprehensively by policy-makers (7). Still, risks of transfer of organisms among biogeographically distinct regions of the Antarctic remain underresearched and poorly regulated (8).

Increasing human activity in the region means escalating risks of pollution from vessel emergencies (at least 12 over the past 5 years) (9) and from point-source discharges. Although marine noise pollution is not thought to pose a major threat in the region, inadequate research leaves policy responses dependent on information from elsewhere. Wildlife disturbance is likely to increase with growing numbers of visitors, especially to popular sites. Identification of long-term consequences of such disturbance is hindered by the lack of appropriate surveys.

Diversification of both science (e.g., intensified subglacial drilling activity) and tourism (e.g., polar crossings) challenge regulatory responses (10). Activities adjacent to protected areas may be reducing the values these areas were designated to protect (8). The Committee for Environmental Protection, responsible for advising Antarctic Treaty Parties about conservation measures and implementation (1), has yet to adopt a dynamic conservation planning approach
Changing environments and resource demands present challenges to Antarctic conservation. for protected areas. As conservation challenges increase with growing environmental change and human impacts, the need to undertake dynamic planning and implementation will grow. Such planning is a hallmark in many other areas and necessary tools are available or being developed (11), but data on the distribution of biodiversity will have to be improved.

Over the longer term ( $\sim 50$ years), growing global human populations and life-style expectations will increase resource demands (12) and, without greater commitment to mitigation, escalation of conservation challenges associated with greenhouse gas emissions. Consequences of climate change will bring pressure to consider geoengineering solutions (13). Activities that do not reduce $\mathrm{CO}_{2}$ emissions will add to problems associated with ocean acidification, predicted to be most acute in the Southern Ocean (14).

As climate continues to change and technology advances, Antarctic resource extraction, driven by escalating global demand, will become more economically feasible. The Protocol on Environmental Protection to the Antarctic Treaty prohibits "any activity relating to mineral resources, other than scientific research." However, this can change should a binding legal agreement on exploitation be reached (Article 25.5) (15). Nations outside the treaty are not bound by its provisions. Although the challenges of working in the Antarctic are considerable, technologies for oil, gas, and mineral exploitation in remote regions have been developed or are advancing rapidly. Two recent developments bear out the proposal. First, several claimant states have made submissions to the United Nations Commission on the Limits of the Continental Shelf about the possibility of asserting shelf claims offshore of their Antarctic territories (16), claims for which are in abeyance under the treaty $(1)$. Second, a submission to the XXXIV Antarctic Treaty Consultative Meeting announced that achievement of the Russian Federation's scientific objectives would help to "strengthen
${ }^{1}$ Stellenbosch University. ${ }^{2}$ Monash University. ${ }^{3}$ British Antarctic Survey. ${ }^{4}$ Antarctic and Southern Ocean Coalition. ${ }^{5}$ Victoria University of Wellington. ${ }^{6}$ Australian Antarctic Division, Department of Sustainability, Environment, Water, Population and Communities. ${ }^{7}$ University of the Western Cape. ${ }^{8}$ International Association of Antarctica Tour Operators. ${ }^{9} 32$ Lyme Street, London NW1 0EE, UK. ${ }^{10}$ French Polar Institute Paul-Emile Victor. ${ }^{11}$ Unité Mixte de Recherche Ecobio Centre National de la Recherche Scientifique, Université de Rennes. ${ }^{12}$ International Union for Conservation of Nature. ${ }^{13}$ Texas A\&M University. ${ }^{14}$ Wageningen University. ${ }^{15}$ Desert Research Institute. ${ }^{16}$ The University of Queensland. ${ }^{17}$ Commission for the Conservation of Antarctic Marine Living Resources. ${ }^{18}$ University of Cape Town. ${ }^{19}$ Antarctica New Zealand. ${ }^{20}$ Scientific Committee on Antarctic Research. ${ }^{21}$ Scott Polar Research Institute. ${ }^{22}$ Colorado State University.

*Full affiliations for all authors are provided online. †Author for correspondence: steven.chown@monash.edu 


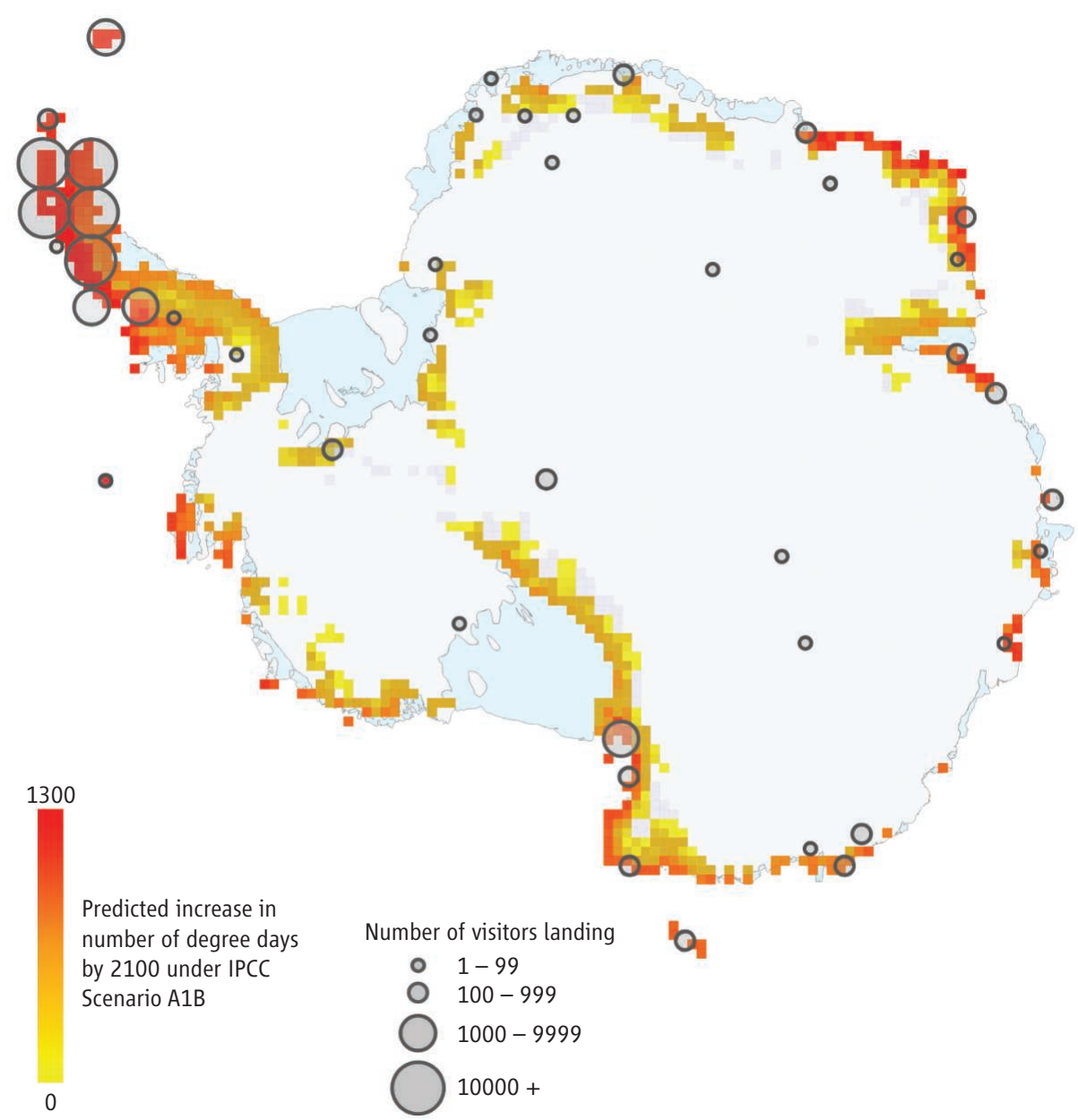

Environmental change in Antarctica. Predicted increase in degree days for vascular plants between 2007-2008 and 2100, overlaid with science and tourist visitor activity in 2007-2008. Data from $(6,8)$.

the economic capacity of Russia through the use of marine biological resources available in the Southern Ocean, and complex investigations of the Antarctic mineral, hydrocarbon and other natural resources" (17). Data to evaluate hydrocarbon and mineral deposits could be gathered, with attendant environmental risks, as part of legitimate scientific programs. Managing activities that bridge research and exploitation is a challenge for other international agreements.

Marine resource harvesting for human consumption is a current threat. Bioprospecting in the region could represent a further challenge if it leads to substantive nondisclosure of information. Information sharing has been a challenge within the treaty (1), and profit-motivated restrictions would further hamper dynamic spatial conservation planning and management $(8,11)$.

Discussions about permanent settlements of parts of Antarctica have typically revolved around the activities of some claimant states. However, as tourism diversifies and includes more land-based compo- nents, and as science and tourism ventures share resources (18), the probability of more permanent residents will increase, as is the case for those who serve these industries on the Arctic island of Svalbard. Permanent human settlements can be acceptable within the charge to use the continent for "peaceful purposes" but are likely to bring a broad range of conservation challenges. Although the treaty has provisions to deal with conservation threats, it does not currently regulate resident citizens.

The five decades since entry into force of the Antarctic Treaty have seen a quickening in the pace of global change, reflected in accelerating rates of ice loss in the Antarctic (19). Growing use of the continent together with such change will mean substantial impacts on ecosystems, including those that are globally unmatched, such as in the McMurdo Dry Valleys. The capability of current conservation governance arrangements to deal with these challenges may be outpaced.

The scientific community can help address these challenges by investigating their nature, extent, and trajectories and by making the outcomes more rapidly and readily accessible to the policy environment. Action to adapt to and mitigate the consequences of change must be taken by all Antarctic visitors, operators, and national programs. The most potential for effective action lies with the Antarctic Treaty System itself. This will require improved ways to use scientific information effectively and an increase in the speed of decision-making. The greatest challenge will be addressing threats that are global in scale, but with impacts that are being realized most significantly in the Antarctic. To do so requires greater engagement with other international environmental policy instruments and organizations.

\section{References and Notes}

1. P. A. Berkman, M. A. Lang, D. W. H. Walton, Eds., Science Diplomacy: Antarctica, Science, and the Governance of International Spaces (Smithsonian Institution Scholarly Press, Washington, DC, 2011).

2. W. J. Sutherland et al., Trends Ecol. Evol. 27, 12 (2012).

3. For a description of the approach and participants and additional information, see supplementary materials.

4. T. Tin et al., Antarct. Sci. 21, 3 (2009).

5. L. K. Blight et al., Science 330, 1316 (2010).

6. S. L. Chown et al., Proc. Natl. Acad. Sci. U.S.A. 109, 4938 (2012).

7. Committee for Environmental Protection, Non-native Species Manual (2011); www.ats.aq/documents/atcm34/ ww/atcm34_ww004_e.pdf.

8. A. Terauds et al., Divers. Distrib. 18, 726 (2012).

9. V. Ruoppolo, E. J. Woehler, K. Morgan, C. J. Clumper, Polar Rec. (Great Britain) 10.1017/S0032247411000763 (2012).

10. Antarctic Treaty Consultative Meeting XXXIV Information Paper 18, www.ats.aq/documents/ATCM34/ip/ATCM34_ ip018_e.doc.

11. D. B. Segan, E. T. Game, M. E. Watts, R. R. Stewart, H. P. Possingham, Environ. Model. Softw. 26, 1434 (2011).

12. G. Dyer, Climate Wars: The Fight for Survival as the World Overheats (Oneworld Publications, Oxford, 2010).

13. N. E. Vaughan, T. M. Lenton, Clim. Change 109, 745 (2011).

14. B. I. McNeil, R. ]. Matear, Proc. Natl. Acad. Sci. U.S.A. 105, 18860 (2008)

15. Protocol on Environmental Protection to the Antarctic Treaty, www.ats.aq/documents/recatt/Att006_e.pdf.

16. C. C. Joyner, in (1), pp. 97-102.

17. Antarctic Treaty Consultative Meeting XXXIV Working Paper 55, www.ats.aq/documents/ATCM34/wp/ATCM34_ wp055 e.doc.

18. Antarctic Treaty Consultative Meeting XXXII Information Paper 23, www.ats.aq/documents/ATCM32/ip/ATCM32 ip023_rev1_e.doc.

19. E. Rignot, I. Velicogna, M. R. van den Broeke, A. Monaghan, J. Lenaerts, Geophys. Res. Lett. 38, L05503 (2011).

Acknowledgments: Views expressed here reflect authors personal perspectives, not necessarily the policy positions of their home organizations. This work was supported by the Scientific Committee on Antarctic Research, Antarctica New Zealand, the South African National Research Foundation, and a Martha T. Muse award (S.L.C.). A. Macey, N. Gilbert, and M. McGeoch provided useful comments.

\section{Supplementary Materials}

www.sciencemag.org/cgi/content/full/337/6091/158/DC1

10.1126/science. 1222821 